\title{
Okadaic acid activates the PKR pathway and induces apoptosis through PKR stimulation in MG63 osteoblast-like cells
}

\author{
TATSUJI HANEJI ${ }^{1}$, KANJI HIRASHIMA $^{1}$, JUMPEI TERAMACHI ${ }^{1}$ and HIROYUKI MORIMOTO ${ }^{2}$ \\ ${ }^{1}$ Department of Histology and Oral Histology, Institute of Health Biosciences, The University of Tokushima Graduate School, \\ Kuramoto, Tokushima 770-8504; ${ }^{2}$ Department of Anatomy, School of Medicine, University of Occupational \\ and Environmental Health, Yahatanishi, Kitakyushu 807-8555, Japan
}

Received February 19, 2013; Accepted March 27, 2013

DOI: $10.3892 /$ ijo.2013.1911

\begin{abstract}
Double-stranded RNA-dependent protein kinase (PKR) is one of the players in the cellular antiviral responses and is involved in transcriptional stimulation through activation of $N F-\kappa B$. Treatment of the human osteosarcoma cell line MG63 with the protein phosphatase inhibitor okadaic acid stimulated the expression and phosphorylation of $I \kappa B \alpha$, as judged from the results of real-time PCR and western blot analysis. We investigated the functional relationship between PKR and signal transduction of $N F-\kappa B$ by establishing PKR-K/R cells that produced a catalytically inactive mutant of PKR. Phosphorylation of eIF-2 $\alpha$, a substrate of PKR, was not stimulated by okadaic acid in the PKR-K/R cells, whereas okadaic acid induced phosphorylation of eIF-2 $\alpha$ in MG63 cells. Phosphorylation of NF- $\kappa \mathrm{B}$ in MG63 cells was stimulated by okadaic acid; however, okadaic acid did not induce phosphorylation of $\mathrm{NF}-\kappa \mathrm{B}$ in the PKR-K/R cells. Finally, okadaic acid-induced apoptosis was inhibited in the PKR-K/R cells. Our results suggest that okadaic acid-induced phosphorylation of $\mathrm{I} \kappa \mathrm{B} \alpha$ was mediated by PKR kinase activity, thus, indicating the involvement of this kinase in the control mechanism governing the activation of $N F-\kappa B$ and induction of apoptosis.
\end{abstract}

\section{Introduction}

Double-stranded RNA-dependent protein kinase (PKR) is an abundantly expressed serine/threonine protein kinase which is activated by double-stranded RNA (dsRNA), interferons, cytokines, stress signals, and viral infection $(1,2)$. PKR is also involved in several signal transduction pathways, such

Correspondence to: Professor Tatsuji Haneji, Department of Histology and Oral Histology, Institute of Health Biosciences, The University of Tokushima Graduate School, 3-18-15 Kuramoto, Tokushima 770-8504, Japan

E-mail: tat-hane@tokushima-u.ac.jp

Key words: $\mathrm{PKR}, \mathrm{I} \kappa \mathrm{B} \alpha, \mathrm{NF}-\kappa \mathrm{B}$, phosphorylation, dephosphorylation, okadaic acid as mitogen-activated protein kinase (MAPK), nuclear factor of $\kappa \mathrm{B}(\mathrm{NF}-\kappa \mathrm{B})$, inhibitor of NF- $\kappa \mathrm{B}$ (I $\kappa \mathrm{B})$ and Smad (3-5). PKR is activated through autophosphorylation and once activated the enzyme phosphorylates certain substrates including the $\alpha$-subunit of eukaryotic initiation factor 2 (eIF-2 $\alpha)(6,7)$. The PKR-eIF-2 $\alpha$ cascade has been implicated as a general transducer of apoptosis in response to a variety of stimuli (8-12). It was reported that PKR was dephosphorylated by serine/ threonine protein phosphatases type 1 (PP1) $(13,14)$. PP1 binds directly to PKR and reduces dsRNA-mediated auto-activation of PKR (15). PP1 may regulate the activities of both PKR and eIF- $2 \alpha$ by dephosphorylating them and thus might block the protein synthesis and apoptosis.

Apoptosis is one of the essential steps in the maintenance of normal cell populations of adult mammals and occurs continually in various cell populations. Apoptosis is a morphologically and biochemically distinct mode of cell death that plays major roles during embryogenesis, carcinogenesis, cancer treatment, or immune and toxic cell killing (16-20). The cytological apparent stages of apoptosis are rapid condensation of chromatin and fragmentation of the cells with membrane-enclosed apoptotic bodies that are phagocytosed and digested by nearby resident cells (21). A biochemical characteristic feature of the process is double-strand cleavage of nuclear DNA at the linker regions between nucleosomes, leading to the production of oligonucleosomal fragments with $180-200 \mathrm{bp}$, which results in a characteristic laddering pattern on agarose gel electrophoresis $(22,23)$.

Okadaic acid (OA) is a toxic polyether fatty acid produced by several dinoflagellates and is a potent inhibitor of PP1 and PP2A. The use of this agent has led to the understanding that the phosphorylation and dephosphorylation status is related to cellular regulation, including the biological end-point, apoptosis (24-26). We previously reported that OA induced apoptosis in human osteoblastic cells (27-29). Protein kinases and phosphatases were reported to be involved in transcriptional stimulation through activation of the $\mathrm{NF}-\kappa \mathrm{B}$ pathway $(15,30)$. We reported that the PKR/eIF-2 $\alpha$ pathway was activated and that $\mathrm{NF}-\kappa \mathrm{B}$ translocation occurred during the OA-induced apoptosis $(7,31)$. However, details of the mechanisms of OA-mediated expression and phosphorylation of I $\mathrm{B}$ and $N F-\kappa B$ are still obscure. The relationship between I $\mathrm{B}$ or $\mathrm{NF}-\kappa \mathrm{B}$ and PKR in apoptosis is also to be determined. 


\section{Materials and methods}

Reagents. G418 Geneticin, cycloheximide (CHX), and anti- $\beta$ actin antibody were obtained from Sigma-Aldrich (St. Louis, MO, USA). $\alpha$-modification of minimum essential medium $(\alpha$-MEM), Opti-MEM, and pre-stained molecular weight markers were purchased from Gibco BRL (Grand Island, NY, USA). FuGene HD was from Roche (Indianapolis, IN, USA). Fetal bovine serum (FBS) was obtained from Equitech-Bio (Kerrville, TX, USA). Anti-phospho-eIF-2 $\alpha$ (119A11) antibody was from Cell Signaling (Danvers, MA, USA). Anti-phospho-

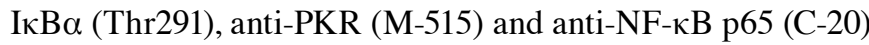
antibodies were from Santa Cruz Biotechnology (Santa Cruz, CA, USA). Antibody for I $\mathrm{KB} \alpha$ (MAD-3) were obtained from BD Biosciences (San Jose, CA, USA). Plastic dishes were from Iwaki (Chiba, Japan). OA was purchased from Wako (Osaka, Japan).

Cell culture and establishment of the PKR-K/R mutant MG63 cells. Human PKR cDNA and a PKR-K/R mutant cDNA (carrying a mutation of amino acid $\mathrm{K} \rightarrow \mathrm{R}$ at position 296) and their expression vector were kindly provided by Dr A. Hovanessian (Institute Pasteur, Paris, France) (32) and Dr T. Takizawa (Aichi Human Service Center, Aichi, Japan) (33), respectively. Human osteoblastic osteosarcoma cell line MG63 cells were obtained from the American Type Culture Collection (Rockville, MD, USA). The cells were cultured in $\alpha$-MEM containing $10 \%(\mathrm{v} / \mathrm{v})$ FBS and were maintained at $37^{\circ} \mathrm{C}$ in a humidified atmosphere of $5 \% \mathrm{CO}_{2}$ and $95 \%$ air.

PKR-K/R cDNA was subcloned into pcDNA3.1-Flag (modified pcDNA3.1, Invitrogen, Carlsbad, CA, USA). Transfection of pcDNA3.1-Falg-PKR-K/R into MG63 cells was performed using FuGene HD reagents. Two $\mu \mathrm{g}$ of pc-Flag and pc-Flag-PKR-K/R in $100 \mu 1$ Opti-MEM were mixed with $8 \mu \mathrm{l} \mathrm{FuGene} \mathrm{HD} \mathrm{reagent} \mathrm{for} 15 \mathrm{~min}$ at ambient temperature. The DNA-FuGene HD complex was then added into $35-\mathrm{mm}$ dishes containing $4 \times 10^{5}$ cells. The media were replaced at $24 \mathrm{~h}$ after transfection and the cells were subcultured in medium containing G418 Geneticin at a final concentration of $500 \mu \mathrm{g} /$ $\mathrm{ml}$ for 2 weeks. The media were replenished every 3 days. The drag-resistant colonies were selected and cloned. Cell modification was monitored by an Olympus IMT-2 phase-contrast microscope.

SDS-PAGE and western blot analysis. MG63 cells and their PKR-K/R mutant cells were washed twice with PBS, scraped into lysate buffer containing $1 \mathrm{mM}$ DTT, $1 \mathrm{mM}$ PMSF, $1 \mu \mathrm{g} /$ $\mathrm{ml}$ leupeptin, $2 \mu \mathrm{g} / \mathrm{ml}$ aprotinin, $5 \mathrm{mM}$ EGTA and protein phosphatase inhibitor cocktail (Sigma-Aldrich) in phosphatebuffered saline (PBS). The lysates containing equal amounts of proteins were separated by $10 \%$ SDS-PAGE and transferred to PVDF membranes (Millipore, Bedford, MA, USA). The membranes were incubated for $2 \mathrm{~h}$ at ambient temperature in a blocking solution consisting of 5\% non-fat skim milk in PBS containing $0.1 \%$ Tween-20 (PBS-Tween) and incubated overnight at $4^{\circ} \mathrm{C}$ with specific antibodies in PBS-Tween (diluted at 1:500 to 10,000). After the membranes had been washed 4 times within $30 \mathrm{~min}$ in PBS-Tween, they were incubated for $2 \mathrm{~h}$ at ambient temperature in PBS-Tween containing horseradish peroxidase-conjugated second antibodies (diluted at 1:5,000).
The membranes were washed again as described above and the proteins recognized by the antibodies were visualized with an ECL detection kit (Pharmacia Biotech, Uppsala, Sweden) according to the manufacturer's instuctions. To strip off the antibody the membrane was treated for $30 \mathrm{~min}$ at $50^{\circ} \mathrm{C}$ with $2 \%$ SDS and $0.35 \%$ 2-mercaptoehanol in $62.5 \mathrm{mM}$ Tris- $\mathrm{HCl}$ (pH 6.8). The antibody-stripped membrane was then blocked again and re-incubated with other antibodies.

RNA preparation, real-time $P C R$, and $R T-P C R$. MG63 cells and the PKR-K/R cells were cultured in $35-\mathrm{mm}$ dishes (1.0x10 ${ }^{4}$ cells/dish). Quantitative real-time PCR analysis was performed using SYBER Premix Ex taq Perfect Real-time (Takara Bio, Kyoto, Japan). The sequences of the primers used are as follows: I $\mathrm{B} \alpha$ forward, CACACGTGTCTACACTTAG CCTCTA; IкB $\alpha$ reverse, AATAGCCCTGGTAGGTAACTC TGTT; GAPDH forward, GACCCCTTCATTGACCTCAAC; GAPDH reverse, CTTCTCCATGGTGGTGAAGA. DNA amplification and detection was performed in the ABI PRISM 7500 (Perkin-Elmer Applied Biosystems, Foster City, CA, USA). PCR amplification (40 cycles) was performed following conditions: $95^{\circ} \mathrm{C}$ for $10 \mathrm{sec}$ and $60^{\circ} \mathrm{C}$ for $34 \mathrm{sec}$. Standard curves were generated using 10 -fold serial dilutions of genomic DNA. The concentrations of unknown samples were calculated by extrapolation from this standard curve and expression levels were normalized with GAPDH expression. The data were analyzed by Sequence Detection Software (SDS) vo1. 4 (Perkin-Elmer).

For RT-PCR analysis, total cellular RNA was extracted by using TRIzol (Invitrogen) and subjected to PCR using RT-PCR kit (Takara). The primers used for PCR were as indicated above. $\mathrm{PCR}$ reactions at $94^{\circ} \mathrm{C}$ for $30 \mathrm{sec}$, at $57^{\circ} \mathrm{C}$ for $30 \mathrm{sec}$ and at $72^{\circ} \mathrm{C}$ for $30 \mathrm{sec}$ were carried out for 32 cycles. The PCR products were separated by electrophoresis on $1.5 \%$ agarose gels and visualized by ethidium bromide staining with UV light illumination.

DNA isolation and agarose gel electrophoresis. Purification of DNA from cultured cells was started by lysis of the cells in cold $10 \mathrm{mM}$ Tris-HCl, $\mathrm{pH}$ 7.5, containing $1 \mathrm{mM}$ EDTA and $0.5 \%$ Triton $\mathrm{X}-100$. After lysis, debris was removed by centrifugation at $15,000 \mathrm{~g}$ for $20 \mathrm{~min}$. DNAse-free RNAse (Sigma-Aldrich) was added to the lysates at a final concentration of $40 \mu \mathrm{g} / \mathrm{ml}$, and the lysates were then incubated with gentle shaking for $1 \mathrm{~h}$ at $37^{\circ} \mathrm{C}$. Proteinase K (Sigma-Aldrich) was added to the RNAse-treated lysates at a final concentration of $40 \mu \mathrm{g} / \mathrm{ml}$. The lysates were further incubated for $1 \mathrm{~h}$ at $37^{\circ} \mathrm{C}$ with gentle shaking. DNA was precipitated with 2-propanol and sodium chloride overnight at $-20^{\circ} \mathrm{C}$. After centrifugation and drying, the DNA was dissolved in TE-buffer $(10 \mathrm{mM}$ Tris, $\mathrm{pH}$ 8.0, containing $1 \mathrm{mM}$ EDTA). Agarose gel electrophoresis of DNA was performed by using $2.0 \%$ agarose gel containing $0.5 \mu \mathrm{g} / \mathrm{ml}$ ethidium bromide. DNA markers (100 bp) (New England BioLabs, Ipswich, MA, USA) were run in the same gels. To visualize apoptotic alterations to DNA integrity, we observed the DNA bands on a UV transilluminator. Images were taken with a Polaroid DS-300 camera.

Statistical analysis. All data are presented as mean \pm SEM. Statistical analysis was performed using Student's t-test. 
Results are representative examples of three or more independent experiments.

\section{Results}

Okadaic acid stimulated the expression of $I \kappa B \alpha$ in $M G 63$ cells. Fig. 1A shows that the anti-I $\kappa \mathrm{B} \alpha$ antibody recognized a band corresponding to $\mathrm{I} \kappa \mathrm{B} \alpha(36 \mathrm{kDa})$ in a sample prepared from the unstimulated MG63 cells. OA at $50 \mathrm{nM}$ increased the expression of $\mathrm{I} \kappa \mathrm{B} \alpha$ protein in a time-dependent manner (Fig. 1A, upper panel). The anti-phospho-IкB $\alpha$ (S32) antibody interacted with a band corresponding to $\mathrm{I} \kappa \mathrm{B} \alpha$ and $50 \mathrm{nM}$ OA increased the staining intensity of phosphorylated $\mathrm{I} \kappa \mathrm{B} \alpha$ in MG63 cells (Fig. 1A, middle panel). The bound antibodies were stripped off the membranes and re-incubated with the anti- $\beta$-actin antibody as loading controls (Fig. 1A, lower panel). A band corresponding to the position of $\mathrm{I} \kappa \mathrm{B} \alpha$ was not detected in the blots of the extracts incubated with the same dilution of normal rabbit serum (data not shown). We also analyzed the expression of I $\mathrm{B} \alpha \mathrm{mRNA}$. The result of RT-PCR shows that $\mathrm{OA}$ increased the expression of I $\mathrm{B} \alpha \mathrm{mRNA}$ in MG63 cells (Fig. 1B).

New protein synthesis in MG63 cells was inhibited by the treatment of $100 \mathrm{ng} / \mathrm{ml}$ of $\mathrm{CHX}$ for $30 \mathrm{~min}$. The expression of I $\mathrm{B} \alpha$ protein was evaluated by western blot analysis. OA-treatment decreased the staining intensity of IкB $\alpha \leq 2 \mathrm{~h}$, at which time the staining level was minimum. After that the staining level increased in a time-dependent manner up to $6 \mathrm{~h}$ (Fig. 2). The amounts of I $\mathrm{B} \alpha$ decreased in MG63 cells treated with OA for $2 \mathrm{~h}$ in a dose-dependent fashion up to $100 \mathrm{nM}$ (data not shown). These findings indicate that $\mathrm{I} \kappa \mathrm{B} \alpha$ was degraded in MG63 cells with OA-treatment. The expression of $\beta$-actin was not changed with OA-treatment (Fig. 2).

Expression of eIF-2 $\alpha$ and PKR in the okadaic acid-treated cells. PKR functions via phosphorylation of IкB $\alpha(34,35)$ and $\mathrm{OA}$ increased the amounts of phosphorylated form of $\mathrm{I} \kappa \mathrm{B} \alpha$ (Fig. 1). We considered that PKR might play an essential role in the phosphorylation of $\mathrm{I} \kappa \mathrm{B} \alpha$. We transfected MG63 cells with a catalytically inactive mutant of human PKR obtained by substituting Lys at 296 with Arg and established cells stably expressing dominant-negative PKR gene (PKR-K/R). To verify the PKR mutation, we analyzed the phosphorylation status of eIF-2 $\alpha$, the best-characterized substrate of PKR, by western blotting using an anti-phospho-eIF- $2 \alpha$ antibody. Fig. 3 shows that the intensity of phosphorylated form of eIF- $2 \alpha$ increased in the $50 \mathrm{nM}$ OA-treated pcDNA-transfected MG63 cells (pc cells). However, the level of this form was low in the PKR-K/R cells treated with OA at the same conditions (Fig. 3). The amounts of eIF-2 $\alpha$ did not differ between the control and PKR-K/R cells. OA increased the amount of PKR in the PKR-K/R cells whereas the expression levels of PKR were low in the OA-treated pc cells (Fig. 3). These data indicate that although PKR was overexpressed in PKR-K/R cells, functional PKR/eIF-2 $\alpha$ pathway was inactivated by the transfection with the plasmid bearing the PKR dominantnegative mutation.

We treated pc and PKR-K/R cells with $50 \mathrm{nM} O A$ for various time-points. Expression of $\mathrm{I} \kappa \mathrm{B} \alpha$ was detected in the samples of the unstimulated pc cells whereas the expression
A
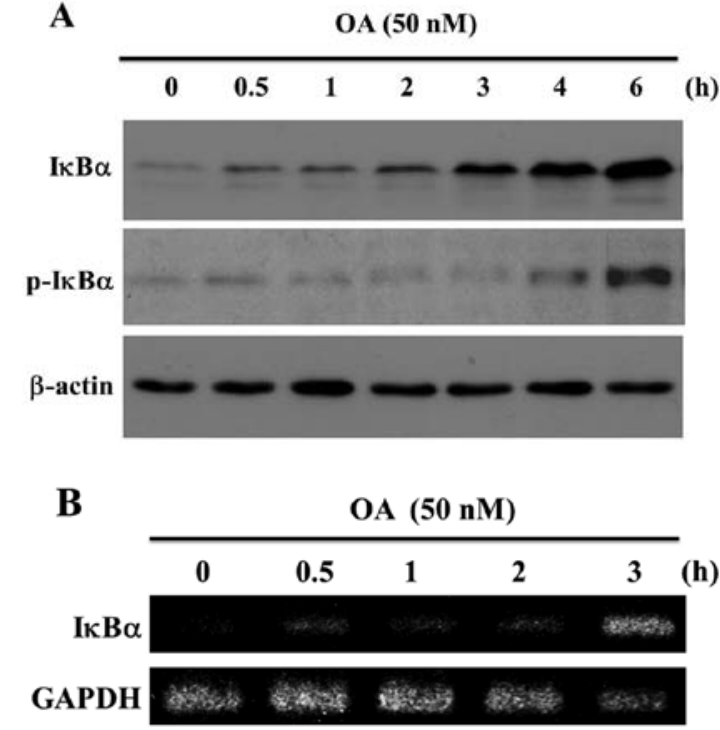

Figure 1. Expression of $\mathrm{I} \kappa \mathrm{B} \alpha$ in the OA-treated cells. (A) After having reached the confluence, MG63 cells were treated for various time periods with $50 \mathrm{nM}$ OA. Twelve $\mu \mathrm{g}$ of each protein was separated on $10 \%$ of SDS-PAGE gels, transferred to PVDF membranes and incubated with antibodies specific for $\mathrm{I} \kappa \mathrm{B} \alpha$ (upper panel) and anti-phospho-I $\mathrm{B} \alpha$ (middle panel), respectively. The bound antibodies were stripped off the membranes and re-incubated with anti- $\beta$-actin antibody as loading controls (lower panel). (B) Total cellular RNA was extracted from the OA-treated MG63 cells and subjected to RT-PCR for I $\kappa \mathrm{B} \alpha$ and GAPDH for the control.

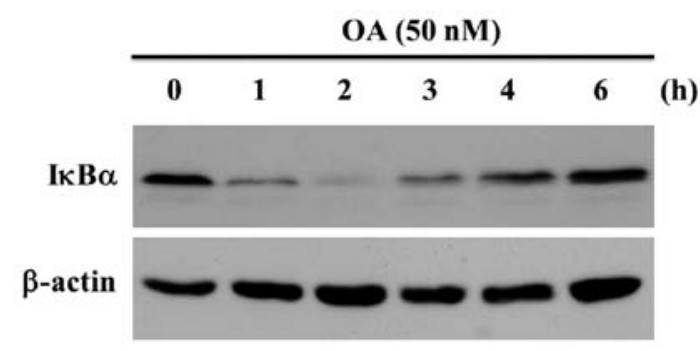

Figure 2. Degradation of $\mathrm{I} \kappa \mathrm{B} \alpha$ in MG63 cells treated with OA. New protein synthesis in MG63 cells was inhibited by $100 \mathrm{ng} / \mathrm{ml}$ of CHX for $30 \mathrm{~min}$. The cells were treated with $50 \mathrm{nM}$ OA for various time courses as indicated (upper panel). The samples from the OA-treated cells were analyzed by western blotting with anti-IкB $\alpha$ antibody. The loading control done with $\beta$-actin is shown in the lower panel.

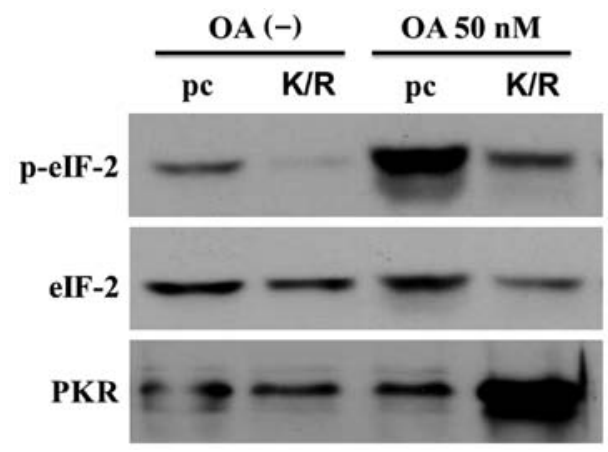

Figure 3. Expression of eIF-2 $\alpha$ and PKR in the OA-treated cells. The established pc and PKR-K/R cells were cultured with $50 \mathrm{nM}$ OA for $6 \mathrm{~h}$. Phosphorylated eIF- $2 \alpha$ and eIF- $2 \alpha$ were detected with anti-phospho-eIF- $2 \alpha$ and anti-eIF-2 $\alpha$ antibodies, respectively. The cell lysates from the pc and PKR-K/R cells were analysed for the expression of PKR protein with antiPKR antibody. 
$\mathbf{A}$

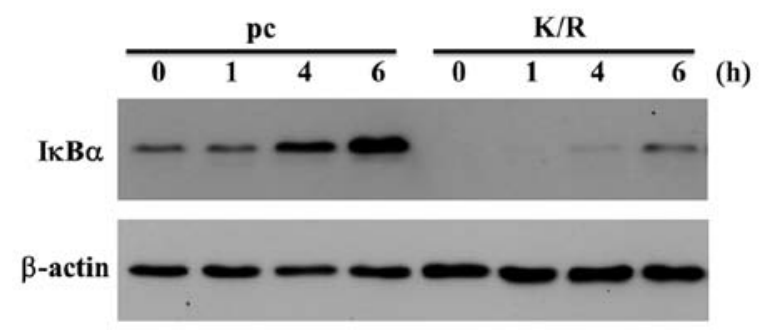

B

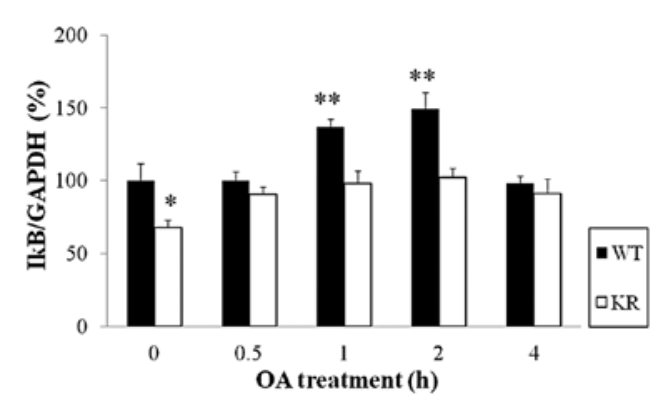

Figure 4. Expression of $\mathrm{I} \kappa \mathrm{B} \alpha$ in $\mathrm{pc}$ and PKR-K/R cells. (A) The pc and $\mathrm{PKR}-\mathrm{K} / \mathrm{R}$ cells were treated for various time periods with $50 \mathrm{nM} \mathrm{OA}$. The expression of $\mathrm{I} \kappa \mathrm{B} \alpha$ was analyzed by western blotting. Loading controls were done with anti- $\beta$-actin antibody. (B) The expressions of I $\mathrm{B} \alpha \mathrm{mRNA}$ in MG63 and PKR-K/R cells were analyzed by real-time PCR. Significan differences from the control cultures are indicated by asterisks; ${ }^{*} \mathrm{P}<0.05$; ${ }^{* *} \mathrm{P}<0.01$; WT, MG63 cells; KR, PKR-K/R cells.

levels of $\mathrm{I} \kappa \mathrm{B} \alpha$ were low in the PKR-K/R cells (Fig. 4A). OA increased the I $\kappa \mathrm{B} \alpha$ expression in pc cells compared with that in PKR-K/R cells (Fig. 4A). The bound anti-I $\kappa \mathrm{B} \alpha$ antibody was stripped off and re-incubated with anti- $\beta$-actin antibody as a loading control (Fig. 4A). The result of real-time PCR shows that the expression of $\mathrm{I} \kappa \mathrm{B} \alpha$ mRNA in MG63 cells was stimulated with $50 \mathrm{nM}$ OA in a time-dependent manner (Fig. 4B). The expression of I $\mathrm{B} \alpha$ in the $50 \mathrm{nM}$ OA-stimulated PKR-K/R cells was low compared with that of the wild-type MG63 cells (Fig. 4B).

Regulation of $N F-\kappa B$ proteins in the cells treated with okadaic acid. To determine the expression of $\mathrm{NF}-\kappa \mathrm{B}$ in $\mathrm{pc}$ and PKR-K/R cells whole cell lysates prepared from the $50 \mathrm{nM}$ OA-stimulated cells were analyzed by western blotting with an antibody against p65NF- $\mathrm{B}$. The anti-p65NF- $\mathrm{kB}$ antibody interacted with a major band having an estimated molecular weight of $65 \mathrm{kDa}$ (Fig. 5, upper panel). This antibody also recognized a more slowly migrating band in the OA-treated pc cells. The levels of slowly migrated bands in the PKR-K/R cells were low compared with that in the pc cells (Fig. 5). These slower migrated bands were not detected in the extracts prepared from the unstimulated cells. The slowly migrated band was a phosphorylated form of NF- $\mathrm{B}$ (31). Fig. 5 also shows that the anti-phospho-Ser536 p65NF- $\kappa \mathrm{B}$ antibody interacted with a $65-\mathrm{kDa}$ band and $\mathrm{OA}$ increased the staining intensity of the band in pc and PKR-K/R cells. However, the staining intensity was higher in pc cells than that in the PKR-K/R cells (Fig. 5, middle panel). The bound antibody was stripped off the membrane and re-incubated with anti- $\beta$-actin antibody for the loading controls (Fig. 5, lower panel).

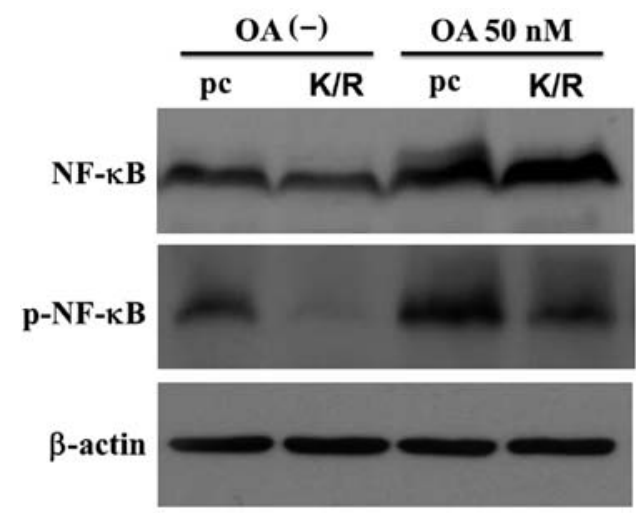

Figure 5. Western blot analysis of NF- $\mathrm{KB}$ in OA-treated cells. The pc and PKR-K/R cells were treated with $50 \mathrm{nM}$ OA for $6 \mathrm{~h}$ and the cell lysates were prepared from each type of culture. Twelve microgram of each sample was separated on a $10 \%$ of SDS-PAGE and transferred to PVDF membranes. Each membrane was then incubated with anti-p65NF- $\mathrm{B}(\mathrm{NF}-\kappa \mathrm{B})$ and antiphospho-Ser536 NF- $\kappa \mathrm{B}(\mathrm{p}-\mathrm{NF}-\kappa \mathrm{B})$ antibodies. The membrane antibody was stripped off and re-incubated with anti- $\beta$-actin antibody as a loading control.

Apoptosis in MG63 and PKR-K/R cells. In our previous study, OA induced apoptosis in MG63 cells (7). We examined whether OA could induce apoptosis in the PKR-K/R cells. To quantify the OA-induced cytotoxicity in MG63 and PKR-K/R cells, the cells were treated with various concentrations of OA for $24 \mathrm{~h}$ and the cell viability was measured by the WST- 8 assay. Fig. 6 shows that OA decreased the cell viability in MG63 cells in a dose-dependent manner up to $100 \mathrm{nM}$. OA at $10 \mathrm{nM}$ decreased the cell viability to $\sim 40 \%$ that of the control cells, whereas the viability of $50 \mathrm{nM}$ OA-treated cells was $20 \%$ that of the control cultures (Fig. 6). OA also decreased the cell viability in PKR-K/R cells (Fig. 6). However, the level of cell viability was higher in the PKR-K/R cells compared with that in the MG63 cells (Fig. 6). The cell viability of PKR-K/R cells treated with $50 \mathrm{nM}$ OA was $40 \%$ that of the control cells (Fig. 6).

To determine if the OA-induced cell viability was due to apoptosis, we looked for the presence of nuclear fragmentation in MG63 and PKR-K/R cells treated with a low (20 nM) or higher $(50 \mathrm{nM})$ concentrations of OA for $48 \mathrm{~h}$. The extracted DNA was analyzed by agarose gel electrophoresis and stained with ethidium bromide. In the $50 \mathrm{nM}$ OA-treated MG63 cells, a DNA fragmentation pattern forming a ladder of multiples of 185-200 bp was observed (Fig. 7A). However, DNA laddering pattern was minimum in the PKR-K/R cells treated with the same concentration of OA. OA at $20 \mathrm{nM}$ also stimulated the DNA laddering pattern in MG63 cells however the same concentration of OA did not induce DNA laddering in the PKR-K/R cells (Fig. 7A). We also evaluated the nuclear fragmentation and condensation of chromatin in MG63 and PKR-K/R cells by Hoechst staining. The control cells did not show any apoptotic features in MG63 cells and PKR-K/R cells (Fig. 7Ba and c). In the $50 \mathrm{nM}$ OA-treated MG63 cells nucleic acid staining with Hoechst 33342 exhibited typical apoptotic nuclei, which had highly fluorescent condensed chromatin structures (Fig. 7Bb). However, in the PKR-K/R cells, the number of the apoptotic cells significantly decreased, although the cells still manifested apoptotic features (Fig. 7Bd). 


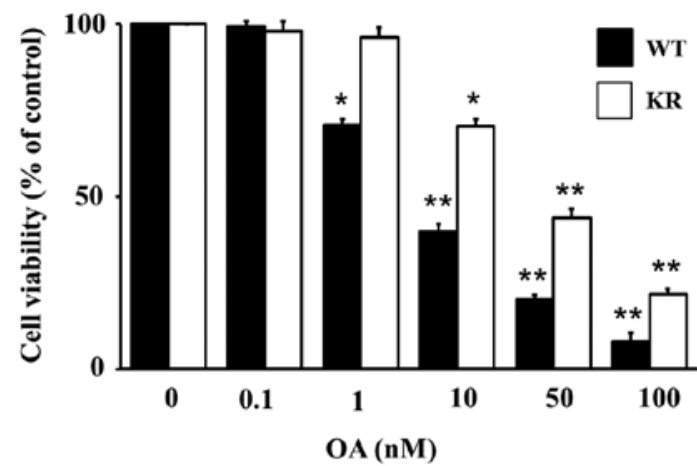

Figure 6. Effects of OA on cell viability in MG63and PKR-K/R cells. MG63 (WT) or PKR-K/R (KR) cells grown in 96-well plates were treated for $24 \mathrm{~h}$ with various concentrations of $\mathrm{OA}$ and the cell viability was determined by the WST-8 assay. The activity was compared to the control well of the same cell line and results are expressed as a percentage of the control (means $\pm \mathrm{SEM})(\mathrm{N}=7)$. The absorbance at $405 \mathrm{~nm}$ of the control cultures for MG63 or PKR-K/R were $1.089 \pm 0.082$ or $1.104 \pm 0.088$, respectively. Significant differences from the control cultures are indicated by asterisks; ${ }^{*} \mathrm{P}<0.05 ;{ }^{* *} \mathrm{P}<0.01$ (Student's t-test).

\section{A}

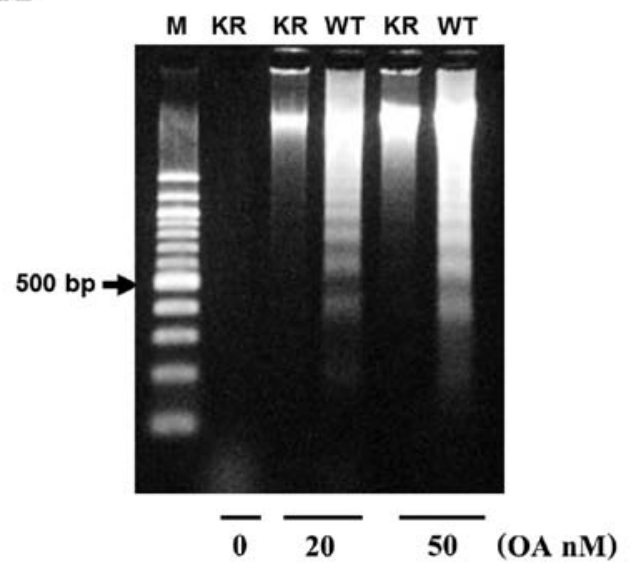

B
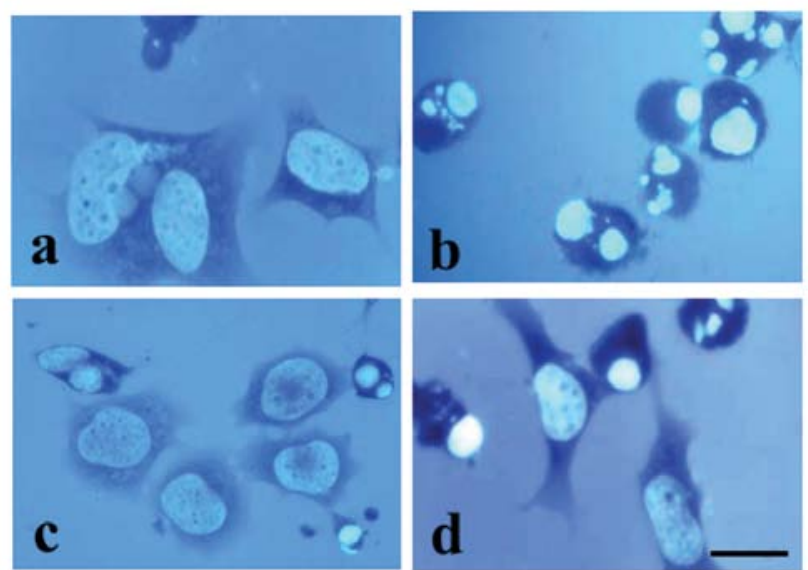

Figure 7. DNA ladder formation (A) and nuclear fragmentation (B) in MG63 and PKR-K/R cells treated with OA. (A) Confluent cells were exposed to OA with low $(20 \mathrm{nM})$ or high $(50 \mathrm{nM})$ concentrations for $48 \mathrm{~h}$. Extracted DNA was electrophoresed through an agarose gel and stained with ethidium bromide. M, standard DNA markers; Arrow indicates 500 bp. (B) Confluent MG63 and PKR-K/R cells were incubated with $50 \mathrm{nM}$ OA for $48 \mathrm{~h}$. The cells were stained with Hoechst 33342 and evaluated the nuclear fragmentation and condensation of chromatin. a, control MG63 cells; b, 50 nM OA-treated MG63 cells; c, control PKR-K/R cells; d, 50 nM OA-treated PKR-K/R cells. Bar represents $10 \mu \mathrm{m}$.

\section{Discussion}

We transfected a human cDNA having the amino acid lysine at 296 replaced with Arginine in the catalytic domain of PKR into human osteoblastic MG63 cells and established the stable cell lines that express mutant gene construct (PKR$\mathrm{K} / \mathrm{R}$ cells). Phosphorylation of eIF- $2 \alpha$ was not detected in the PKR-K/R cells whereas strong phosphorylation of eIF-2 $\alpha$ occurred in pcDNA-transfected MG63 cells. Because eIF-2 $\alpha$ is a substrate for PKR $(6,7)$, the mutant cells we established have a PKR dominant-negative characteristics. OA stimulated the phosphorylation of eIF- $2 \alpha$ in MG63 cells, however, phosphorylation of eIF- $2 \alpha$ in PKR-K/R cells was not stimulated with the OA-treatment.

We explored the effects of $\mathrm{OA}$ on the expression and phosphorylation of I $\kappa \mathrm{B} \alpha$ and p65NF- $\kappa \mathrm{B}$ in MG63 and PKR-K/R cells. During the OA-treatment, the expression and phosphorylation of I $\mathrm{B} \alpha$ increased in MG63 cells. I $\mathrm{B} \mathrm{B} \alpha$ was degraded upon OA treatment in MG63 cells. We previously demonstrated that $\mathrm{I} \kappa \mathrm{B} \alpha$ was phosphorylated on tyrosine residues by the OA-treatment (36). In the present study I $\mathrm{KB} \alpha$ was phosphorylated at least on serine residues at 32 position, because the anti-phospho IкB $\alpha$ (Ser32) recognized the phosphorylated form of I $\mathrm{B} \mathrm{B} \alpha$. We also detected the phosphorylation at Ser36 in MG63 cells (data not shown).

$\mathrm{OA}$ is one of the many stimuli activating NF- $\mathrm{KB}$ in the cultured cells. It has been reported that OA increased the phosphorylation of cellular proteins (24). We previously reported that OA induced activation of PKR/eIF-2 $\alpha$, nuclear translocation of p65NF- $\mathrm{kB}$ and apoptosis in MG63 cells $(5,7,31)$. In human neutrophils and HL-60 cells, OA and orthovanadate, an inhibitor of tyrosine phosphatase, stimulated the activation of NF- $\kappa \mathrm{B}$ and rapid degradation of I $\kappa \mathrm{B} \alpha$ (37). The NF- $\kappa \mathrm{B}$ activation was caused by the OA-induced inhibition of PKC $\delta$ and IKK phosphatases or by the OA-induced activation of ERK1, a member of the MAP kinase family (37). These reports indicate that the phosphorylation and degradation of $\mathrm{I} \kappa \mathrm{B} \alpha$ was influenced by OA-sensitive phosphatases. However, it was reported that OA-induced activation of NF- $\mathrm{kB}$ did not depend on the inhibitor properties of OA but rather on the production of reactive oxygen intermediates (38). The phosphorylation of I $\mathrm{B} \alpha$ preceding its degradation occurs on the Ser32 and 36 residues, making it a subject to degradation by proteosomes. These findings consist with our present results. Degradation of I $\kappa \mathrm{B} \alpha$ liberates the NF- $\kappa \mathrm{B}$ complex, which is able to migrate to the nucleus and to activate gene expression (39). In our previous study we demonstrated that $100 \mathrm{nM}$ OA-treatment induced IкB $\alpha$ phosphorylation without causing its degradation. This phosphorylation appears to occur on a tyrosine residue because anti-phospho-tyrosine antibody bound to the samples immunoprecipitated with the anti-IкB $\alpha$ antibody (36). This finding confirms an earlier one that tyrosine phosphorylation of $\mathrm{I} \kappa \mathrm{B} \alpha$ induced NF- $\kappa \mathrm{B}$ activation without its degradation (40). In the present study, we demonstrated that $50 \mathrm{nM}$ OA-treatment induced phosphorylation of $\mathrm{I} \kappa \mathrm{B} \alpha$ on Ser32 residue and degradation of I $\mathrm{B} \alpha$. The discrepancy of the results derived from the use of CHX to block the new protein synthesis in the present study.

PKR is an interferon-induced protein, initially identified and characterized as a translational inhibitor in an antiviral 
pathway regulated by interferon $(1,2)$. It was reported that PKR could function as a signal transducer for mediating transcriptional activation in response to dsRNA via its ability to phosphorylate $\mathrm{I} \kappa \mathrm{B} \alpha$, resulting in the activation of $\mathrm{NF}-\kappa \mathrm{B}$ (41). The relationships between PKR and I $\kappa \mathrm{B} \alpha$ has not been reported previously. To provide a further insight into the role of phosphorylation of $\mathrm{I} \kappa \mathrm{B} \alpha$ in PKR pathway, we used PKR-K/R cells stably expressing the dominant-negative PKR. PKR was earlier found to be associated with IKK complex, where its major contribution appears to be activation of $\mathrm{NF}-\kappa \mathrm{B}(35,41)$. In our previous study, we demonstrated that the mutation of PKR kinase resulted in the basal translocation of p65NF- $\kappa \mathrm{B}$ into the nucleus in the unstimulated cells $(7,31)$. This translocation was accompanied by the degradation of $\mathrm{I} \kappa \mathrm{B} \alpha$. These results indicate that functional PKR is necessary for the cytosolic localization of NF- $\mathrm{NB}$ and for the phosphorylation of $\mathrm{I} \kappa \mathrm{B} \alpha$ in the OA-stimulated cells. Expression of the PKR mutation is associated with enhanced levels of NF- $\kappa \mathrm{B}$ DNA-binding and transcriptional activities compared with those of the control cells (42), further supporting our present results. Serine phosphorylation of $\mathrm{I} \kappa \mathrm{B} \alpha$ and its degradation did not require PKR kinase activity (41). We demonstrated that I $\mathrm{B} \alpha \alpha$ was degraded without phosphorylation in PKR-K/R cells suggesting that the kinase activity of $\mathrm{PKR}$ is required for the phosphorylation of I $\mathrm{B} \alpha$. PKR has Ser/Thr kinase activity; however, it also phosphorylates tyrosine residue in place of Ser51 in eIF-2 $\alpha$ (42). The relationship between kinase activity of PKR and other kinases, such as c-Src, remains to be examined.

PKR is required to osteoblast differentiation, osteoclast formation and chondrogenesis (43-46). Phosphorylation of $\mathrm{I} \kappa \mathrm{B} \alpha$ plays important roles in osteoclastogenesis, osteoclast recruitment and osteolysis $(45,47,48)$. We previously reported that OA induced apoptosis in osteoblastic cells (7,27-31). During OA-induced apoptosis, the PKR/eIF-2 $\alpha$ pathway was activated, that activation was followed by the inhibition of protein synthesis (7). Although the detailed functions of PKR activity in osteoblastic apoptosis remain unclear, it might be possible that PKR mediates the OA-induced apoptosis in MG63 cells by phosphorylating $\mathrm{I} \kappa \mathrm{B} \alpha$ and causing $\mathrm{p} 65 \mathrm{NF}-\kappa \mathrm{B}$ translocation. It still remains to be determined whether an OA-sensitive phosphatase could regulate this pathway.

\section{Acknowledgements}

We thank Mrs. Eiko Sasaki for her skillful technical assistance. This study was supported in part by grants from the Grantin-Aid for Scientific Research from the Ministry of Education, Science, Sports and Culture of Japan (T.H. and H.M.).

\section{References}

1. Sadler AJ and Williams BRG: Interferon-inducible antiviral effectors. Nat Rev Immunol 8: 559-568, 2008.

2. Pindel A and Sadler AJ: The role of protein kinase R in the interferon responses. J Interferon Cytokine Res 31: 59-70, 2011.

3. Nallagatla SR, Toroney R and Bevilacqua PC: Regulation of innate immunity through RNA structure and the protein kinase PKR. Curr Opin Struct Biol 21: 119-127, 2011.

4. Pfaller CK, Li Z, George CX and Samuel CE: Protein kinase PKR and RNA adenosine deaminase ADR1: new roles for old players as modulators of the interferon response. Curr Opin Immunol 23: 573-582, 2011.
5. Yang QL, Zhou LY, Mu YQ, Zhou QX, Luo JY, Cheng L, Deng ZL, He TC, Haydon RC and He BC: All-trans retinoic acid inhibits tumor growth of human osteosarcoma by activating Smad signaling-induced osteogenic differentiation. Int J Oncol 41: 153-160, 2012.

6. de Haro C, Méndez R and Santoyo J: The eIF-2 $\alpha$ kinases and the control of protein synthesis. FASEB J 10: 1378-1387, 1996.

7. Morimoto H, Okamura H, Yoshida K, Kitamura S and Haneji T: Okadaic acid induces apoptosis through double-stranded RNA-dependent protein kinase/eukaryotic initiation factor- $2 \alpha$ pathway in human osteoblastic MG63 cells. J Biochem 136: 433-438, 2004.

8. Yeung MC, Liu J and Lau AS: An essential role for the interferoninducible, double-stranded RNA-activated protein kinase PKR in the tumor necrosis factor-induced apoptosis in U937 cells. Proc Natl Acad Sci USA 93: 12451-12455, 1977.

9. Der SD, Yang YL, Weissmann C and Williams BRG: A doublestranded RNA-activated protein kinase-dependent pathway mediating stress-induced apoptosis. Proc Natl Acad Sci USA 94: 3279-3283, 1997

10. Kaufman RJ: Double-stranded RNA-activated protein kinase mediates virus-induced apoptosis: A new role for an old actor. Proc Natl Acad Sci USA 96: 11693-11695, 1999.

11. Gil $\mathrm{J}$ and Esteban M: Induction of apoptosis by the dsRNAdependent protein kinase (PKR): Mechanism of action. Apoptosis 5: 107-114, 2000.

12. Saelens X, Kalai M and Vandenabeele P: Translation inhibition in apoptosis: caspase-dependent PKR activation and eIF2- $\alpha$ phosphorylation. J Biol Chem 276: 41620-41628, 2001.

13. Szyszka R, Kudlicki W, Kramer G, Hardesty B, Galabru J and Hovanessian A: A type 1 phosphoprotein phosphatase active with phosphorylated $M_{r}=68,000$ initiation factor 2 kinase. J Biol Chem 264: 3827-3831, 1989.

14. Jammi NV and Beal PA: Phosphorylation of the RNA-dependent protein kinase regulates its RNA-binding activity. Nucleic Acids Res 14: 3020-3029, 2001.

15. Tan SL, Tareen SU, Melville MW, Blakely CM and Katze MG: The direct binding of the catalytic subunit of protein phosphatase 1 to the PKR protein kinase is necessary but not sufficient for inactivation and disruption of enzyme dimer formation. J Biol Chem 277: 36109-36117, 2002.

16. Jacobson MD, Weil M and Raff MC: Programmed cell death in animal development. Cell 88: 347-354, 1997.

17. Haneji T: Association of protein phosphatase 1 delta with nucleolin in osteoblastic cells and cleavage of nucleolin in apoptosis-inducing osteoblastic cells. Acta Histochem Cytochem 38: 1-8, 2005

18. Tanaka H, Yoshida K, Okamura H, Morimoto H, Nagata T and Haneji T: Calyculin A induces apoptosis and stimulates phosphorylation of p65 NF- $\kappa \mathrm{B}$ in human osteoblastic osteosarcoma MG63 cells. Int J Oncol 31: 389-396, 2007.

19. Lin CC, Kuo CL, Lee MH, Lai KC, Lin JP, Yang JS, Yu CS, Lu CC, Chiang JH, Chueh FS and Chung JG: Wogonin triggers apoptosis in human osteosarcoma U-2 cells through the endoplasmic reticulum stress, mitochondrial dysfunction and caspase-3-dependent signaling pathways. Int J Oncol 39: 217-224, 2011.

20. Li B, Yang Y, Jiang S, Ni B, Chen K and Jiang L: Adenovirusmediated overexpression of BMP-9 inhibits human osteosarcoma cell growth and migration through downregulation of the PI3K/ AKT pathway. Int J Oncol 41: 1809-1819, 2012.

21. Savill J and Fadok V: Corpse clearance defines the meaning of cell death. Nature 407: 784-788, 2000.

22. Wyllie AH: Glucocorticoid-induced thymocyte apoptosis is associated with endogenous endonuclease activation. Nature 284: 555-556, 1980.

23. Gong J, Traganos F and Darzynkiewicz Z: A selected procedure for DNA extraction from apoptotic cells applicable for gel electrophoresis and flow cytometry. Anal Biochem 218: 314-319, 1994.

24. Fernandez JJ, Candenas ML, Souto ML, Trujillo MM and Norte M: Okadaic acid, useful tool for studying cellular processes. Curr Med Chem 9: 229-262, 2002.

25. Goto K, Fukuda J and Haneji T: Okadaic acid stimulates apoptosis through expression of Fas receptor and Fas ligand in human oral squamous carcinoma cells. Oral Oncol 38: 16-22, 2002.

26. Fujita M, Goto K, Yoshida K, Okamura H, Morimoto H, Kito S, Fukuda J and Haneji T: Okadaic acid stimulates expression of Fas receptor and Fas ligand by activation of nuclear factor kappa-B in human oral squamous carcinoma cells. Oral Oncol 40: 199-206, 2004. 
27. Morimoto Y, Ohba T, Kobayashi S and Haneji T: The protein phosphatase inhibitors okadaic acid and calyculin A induce apoptosis in human osteoblastic cells. Exp Cell Res 230: 181-186, 1997.

28. Morimoto H, Morimoto Y, Ohba T, Kido H, Kobayashi S and Haneji T: Inhibitors of protein synthesis and RNA synthesis protect against okadaic acid-induced apoptosis in human osteosarcoma cell line MG63 cells but not in Saos-2 cells. J Bone Miner Metab 17: 266-273, 1999.

29. Kito S, Shimizu K, Okamura H, Yoshida K, Morimoto H, Fujita M, Morimoto Y, Ohba T and Haneji T: Cleavage of nucleolin and argyrophilic nucleolar organizer region associated proteins in apoptosis-induced cells. Biochem Biophys Res Commun 300: 950-956, 2003.

30. Haneji T, Teramachi J, Hirashima K, Kimura K and Morimoto H: Interaction of protein phosphatase $1 \delta$ with nucleophosmin in human osteoblastic cells. Acta Histochem Cytochem 45: 1-7, 2012.

31. Ozaki A, Morimoto H, Tanaka H, Okamura H, Yoshida K, Amorim BR and Haneji T: Okadaic acid induces phosphorylation of p65NF- $\kappa \mathrm{B}$ on serine 536 and activates NF- $\kappa \mathrm{B}$ transcriptional activity in human osteoblastic MG63 cells. J Cell Biochem 99: 1275-1284, 2006.

32. Meurs E, Chong K, Galabru J, Thomas NSB, Kerr IM Williams BRG and Hovanessian AG: Molecular cloning and characterization of the human double-stranded RNA-activated protein kinase induced by interferon. Cell 62: 379-390, 1990.

33. Takizawa T, Ohashi K and Nakanishi Y: Possible involvement of double-stranded RNA-activated protein kinase in cell death by influenza virus infection. J Virol 70: 8128-8132, 1996.

34. Ishii T, Kwon H, Hiscott J, Mosialos G and Koromilas AE: Activation of the I $\kappa \mathrm{B} \alpha$ kinase (IKK) complex by doublestranded RNA-binding defective and catalytic inactive mutants of the interferon-inducible protein kinase PKR. Oncogene 20: 1900-1912, 2001

35. Gil J, García MA, Gomez-Puertas P, Guerra S, Rullas J, Nakano H, Alcamí J and Esteban M: TRAF family proteins link PKR with NF- $\mathrm{BB}$ activation. Mol Cell Biol 24: 4502-4512, 2004.

36. Morimoto H, Ozaki A, Okamura H, Yoshida K, Kitamura S and Haneji T: Okadaic acid induces tyrosine phosphorylation of $\mathrm{I} \kappa \mathrm{B} \alpha$ that mediated by PKR pathway in human osteoblastic MG63 cells. Mol Cell Biochem 276: 211-217, 2005.
37. Miskolci V, Castro-Alcaraz S, Nguyen P, Vancura A, Davidson D and Vancurova I: Okadaic acid induces sustained activation of $\mathrm{NF} \kappa \mathrm{B}$ and degradation of the nuclear $\mathrm{I} \kappa \mathrm{B} \alpha$ in human neutrophils. Arch Biochem Biophys 417: 44-52, 2003.

38. Schmidt, KN, Traenckner EBM, Meier B and Baeuerle PA Induction of oxidative stress by okadaic acid is required for activation of transcription factor NF- $\kappa$ B. J Biol Chem 270: 27136-27142, 1995.

39. Karin M and Lin A: NF- $\kappa \mathrm{B}$ at the crossroads of life and death. Nat Immunol 3: 221-227, 2002.

40. Imbert V, Rupec RA and Livolsi A, et al: Tyrosine phosphorylation of I $\mathrm{B}-\alpha$ activates NF- $\kappa \mathrm{B}$ without proteolytic degradation of IкB- $\alpha$. Cell 86: 787-798, 1996.

41. Bonnet MC, Weil R, Dam E, Hovanessian AG and Meurs EF PKR stimulates NF- $\kappa$ B irrespective of its kinase function by interacting with the IкB kinase complex. Mol Cell Biol 20: 4532-4542, 2000.

42. Lu J, O'Hara EB, Trieselmann BA, Romano PR and Dever TE: The interferon-induced double-stranded RNA-activated protein kinase PKR will phosphorylate serine, threonine, or tyrosine at residue 51 in eukaryotic initiation factor $2 \alpha$. J Biol Chem 274: 32198-32203, 1999.

43. Yoshida K, Okamura H, Amorim BR, Ozaki A, Tanaka H, Morimoto $\mathrm{H}$ and Haneji T: Double-stranded RNA-dependent protein kinase is required for bone calcification in MC3T3-E1 cells in vitro. Exp Cell Res 311: 117-125, 2005.

44. Yoshida K, Okamura H, Amorim BR, Hinode H, Yoshida H and Haneji T: PKR-mediated degradation of STAT1 regulates osteoblast differentiation. Exp Cell Res 315: 2105-2114, 2009.

45. Teramachi J, Morimoto H, Baba R, Doi Y, Hirashima K and Haneji T: Double stranded RNA-dependent protein kinase is involved in osteoclast differentiation of RAW264.7 cells in vitro. Exp Cell Res 316: 3254-3262, 2010.

46. Morimoto H, Baba R, Haneji T and Doi Y: Double-stranded RNA-dependent protein kinase regulates insulin-stimulated chondrogenesis in mouse clonal chondrogenic cells, ATDC-5. Cell Tissue Res 35: 41-47, 2013.

47. Abu-Amer Y, Dowdy SF, Ross FP, Clohisy JC and Teitelbaum SL TAT fusion proteins containing tyrosine 42-deleted I $\mathrm{B} \alpha$ arrest osteoclastogenesis. J Biol Chem 276: 30499-30503, 2001.

48. Clohisy JC, Roy BC, Biondo C, Frazier E, Willis D, Teitelbaum SL and Abu-Amer Y: Direct inhibition of NF- $\kappa$ B blocks bone erosion associated with inflammarory arthritis. J Immunol 171: $5547-5553,2003$ 